Relato de experiência

\title{
A disciplina de Tópicos de Educação Matemática I: afetos e desafetos
}

\author{
The discipline of Topics of Mathematics Eduction I: affections and disaffections \\ La asignatura "Temas de Educación Matemática I": afectos y desafectos
}

\author{
Luana Cristina Baier ${ }^{1}$ \\ [0000-0002-2844-1110] \\ Elenilton Vieira Godoy ${ }^{2}$ \\ [0000-0001-8081-5813] \\ Elisangela de Campos ${ }^{3}$ \\ [0000-0001-9028-8201]
}

\begin{abstract}
Resumo
Este relato de experiência tem como objetivo narrar as experiências de três vozes formadoras ao ministrar, por meio do Ensino Remoto Emergencial (ERE), uma disciplina optativa em um curso de licenciatura em matemática de uma IESP durante a pandemia. Desta forma, apresentamos três narrativas que priorizam o lugar de fala dos/as formadores/as de futuros/as professores/as de matemática e os afetamentos produzidos ao ministrarem a disciplina. A partir das narrativas e de uma breve discussão teórica sobre colaboração, indicamos alguns sentidos que atravessam os três relatos, "Se adaptar ao momento é preciso" e "O trabalho remoto potencializou a colaboração". No primeiro sentido, se destaca que a colaboração foi uma maneira encontrada pelas três vozes docente de se adaptar a necessidade de ministrar uma disciplina durante o Ensino Emergencial Remoto (EMR). No segundo sentido, se identificou que o fato de se acreditar que o trabalho remoto potencializou a colaboração está relacionado a presença que a colaboração exige, apresentado nos relatos por meio do envolvimento intenso de cada voz docente em todas as demandas da disciplina.
\end{abstract}

Palavras-chave: Práticas Colaborativas. Ensino Emergencial Remoto. Formadoras/o. Pandemia.

\section{Abstract}

This report aims to narrate the experiences of three forming voices of teaching through Emergency Remote Education (ERE), an optional subject in a mathematics course at an IESP during the pandemic. We present three narratives that prioritize the place of speech of future mathematics teachers' trainers and the effects of teaching such discipline. From the narratives and a brief theoretical discussion on collaboration, we present a couple of remarks that have crossed all three reports, "Adapting to the moment is necessary" and "Remote work has potentialized collaboration". The first remark highlights that collaboration was found by the three teaching voices as a way to adapt to the need to teach a class during Remote Emergency Teaching (EMR). The second remark, identified as believing that remote work improved collaboration, is related to the presence that collaboration requires, presented in the reports through the intense involvement of each teaching voice in all the demands of the discipline.

Keywords: Collaborative Practices. Remote Emergency Teaching. Trainers. Pandemic.

\footnotetext{
${ }^{1}$ luanacbaier@gmail.com, Mestra em Educação em Ciências e em Matemática, Curitiba/Paraná/Brasil.

2 elenilton@ufpr.br, Doutor em Educação, Professor, Universidade Federal do Paraná, Curitiba/Paraná/Brasil.

33elismat@ufpr.br, Doutora em Educação, Professora, Universidade Federal do Paraná, Curitiba/Paraná/Brasil.
} 


\begin{abstract}
Resumen
I objetivo de este relato de experiencia es narrar las vivencias de tres profesores al dictar, a través de la Enseñanza Remota de Emergencia (ERE), una asignatura optativa de un curso de profesorado de matemática en una Institución Pública de Educación Superior (IPES) durante la pandemia. Para eso, presentamos tres narrativas que destacan el punto de vista de los formadores/as de futuros/as profesores/as de matemática y las emociones por ellos enfrentadas al dictar la asignatura. A partir de las narrativas y una breve discusión teórica sobre colaboración, señalamos algunos ejes que atraviesan los tres relatos, "Es necesario adaptarse al momento" y "El trabajo remoto ha potenciado la colaboración". En el primer eje, se destaca que la colaboración fue una vía encontrada por los tres docentes para adaptarse a la necesidad de dictar una disciplina durante la Enseñanza Remota de Emergencia (EMR). En el segundo, se identificó que el hecho de que se crea que el trabajo remoto potencia la colaboración está relacionado con la presencia que requiere la colaboración, presentada en los relatos a través del intenso compromiso de cada docente en todas las exigencias de la asignatura
\end{abstract}

Palabras claves: Prácticas colaborativas. Enseñanza remota de emergencia. Formadores/as. Pandemia.

\title{
1 Introdução
}

O que nos atravessa quando precisamos reinventar (ou se adequar) a forma como ministramos uma disciplina em um curso de licenciatura em matemática durante uma pandemia? Larrosa (2011) coloca que a experiência pode ser entendida como um acontecimento que nos afeta e nos torna o lugar da experiência, nas palavras do autor "é o que nos passa, o que nos acontece, o que nos toca." (LARROSA, 2002, p. 21). A experiência nessa perspectiva remete a movimento, nos passa, nos toca, nos acontece e causa transformações no sujeito que é espaço da experiência. Entretanto, como pondera Larrosa (2011) essa experiência por ter o sujeito como local é única para cada um, o acontecimento pode ser o mesmo, porém a experiência será única para cada sujeito. E é por pensar na singularidade da experiência que esse relato apresenta as narrativas de três vozes docentes, que ministraram em conjunto uma disciplina optativa para um curso de licenciatura em matemática de uma Instituição de Ensino Superior Pública (IESP) durante a pandemia do Covid-19. Assim, o objetivo deste texto é narrar as experiências de três vozes formadoras ao ministrar, por meio do Ensino Remoto Emergencial (ERE), uma disciplina optativa em um curso de licenciatura em matemática de uma IESP durante a pandemia.

Pensamos ser importante descrever o cenário ao qual as narrativas se referem, nesse caso o momento vivido pela IESP durante a pandemia e a disciplina. Em março de 2020 se fez necessário cuidar da vida, desta forma a IESP anuncia por meio dos canais oficiais a suspensão de todas as suas atividades presenciais, uma medida necessária, mas que reverberou a pergunta "E agora?". Após um período de planejamento e organização à circunstância imposta pela pandemia, a IESP decide manter a suspensão de seu calendário e conduzir as suas atividades de ensino por meio do ERE. Para isso foi construída, após muita discussão com professores/as, estudantes e técnicos/as administrativos, a RESOLUÇÃO № 59/2020-CEPE que

Regulamenta, em caráter excepcional, período especial para o desenvolvimento de atividades de ensino nos cursos de educação superior, profissional e tecnológica da IESP, no contexto das medidas de enfrentamento da pandemia de COVID-19 no País (IESP, 2020, p. 1). 
O parágrafo único, do Art. 1으 resolve sobre como dar-se-á a interação docentes/discentes durante o período de vigência da Resolução, a saber

Parágrafo único. Enquanto permanecer vigente a Resolução № 42/2020CEPE, que dispõe sobre a suspensão dos calendários acadêmicos dos cursos de graduação, pós-graduação e de educação profissional e tecnológica da IESP, a interação docente/estudante durante o período especial somente será realizada de forma remota (IESP, 2020, p. 3).

Por fim, no item "Das Disposições Gerais" a Resolução trata nos Artigos 28, 29 e 30 do caráter totalmente voluntário para as unidades administrativas, corpo docente e corpo discente, bem como da preocupação em não deixar de seguir as medidas de enfrentamento da pandemia do Covid-19 no País.

Art. 28. Fica estabelecido que a oferta de disciplinas e unidades curriculares no período especial é de caráter totalmente voluntário para as unidades administravas e o corpo docente da IESP, reafirmando o princípio de que o direito à vida se sobrepõe a todos os demais, especialmente na situação atual de pandemia de COVID-19.

Art. 29. Fica estabelecido que a solicitação de matrículas nas disciplinas e unidades curriculares ofertadas no período especial é de caráter totalmente voluntário para o corpo discente da IESP, reiterando o 23/06/2020 SEI/IESP 2758925 - Resolução disposto no Art.28 de que o direito à vida se sobrepõe a todos os demais, especialmente na situação atual de pandemia de COVID19.

Art. 30. Fica estabelecido que a oferta de disciplinas e unidades curriculares no período especial não deve constituir ação que resulte em exigir que as/os servidoras/servidores técnico-administrativos da UFPR deixem de seguir as medidas de enfrentamento da pandemia de COVID-19 no País, destacando, uma vez mais, que o direito à vida se sobrepõe a todos os demais, especialmente na situação atual de pandemia de COVID-19 (IESP, 2020, p. 11 e 12).

Ainda sobre a Resolução № 59/2020-CEPE, no item "Das Disposições Gerais", especificamente no Art. 31, são apresentadas as ações pretendidas para a inclusão e letramento digitais e expansão do uso das tecnologias digitais para as comunidades estudantil, docente e técnica-administrativa, a saber.

Art. 31. Caberá à administração central e unidades conexas (pró-reitorias e órgãos suplementares) da IESP manter as seguintes ações com vistas à inclusão e ao letramento digitais, assim como à expansão do uso de tecnologias digitais nas atividades de ensino-aprendizagem para o ensino remoto emergencial nos cursos de educação superior, profissional e tecnológica da IESP, ações essas já implementadas ou em processo de implantação no contexto das medidas de enfrentamento da pandemia de COVID-19 no País:

I. Ações mandas pela Pró-Reitoria de Assuntos Estudantes (PRAE): 
a. empréstimo de computadores para estudantes com cadastro deferido nos programas PROMISAES (Projeto Milton Santos de Acesso ao Ensino Superior) e/ou PROBEM (Programa de Benefícios Econômicos para a Manutenção aos Estudantes) ou ainda estudantes cadastrados/as no Programa de Bolsa Permanência MEC, assim como estudantes não beneficiários dos programas da PRAE, com comprovada fragilidade econômica, matriculados em curso de educação superior, profissional e tecnológica da IESP;

b. aquisição de serviço de conexão à rede internet para estudantes dos cursos de educação superior, profissional e tecnológica da IESP com cadastro deferido no PROMISAES ou PROBEM ou com cadastro avo no PBP-MEC (Programa de Bolsa Permanência do MEC);

c. doação de equipamentos computacionais e de recepção e manutenção dos equipamentos doados, com a participação da Pró-Reitoria de Administração (PRA), por meio da Agência de Tecnologia da Informação e Comunicação (AGTIC);

d. apoio e suporte psicológico às/aos estudantes, por meio da sua Unidade de Apoio Psicossocial (UAPS/PRAE), com participação do Programa IESP ConVida.

II. Ações mandas pela Pró-Reitoria de Graduação e Educação Profissional (PROGRAD):

a. capacitação docente e discente para desenvolvimento de atividades de ensino remoto emergencial, por meio da Coordenadoria de Integração de Políticas de Educação a Distância (CIPEAD), com participação da PróReitoria de Gestão de Pessoas (PROGEPE);

b. disponibilização, manutenção, oferta e treinamento para o uso da plataforma online, IESP Virtual, como espaço institucional para a realização de atividades assíncronas, por meio da Coordenadoria de Integração de Políticas de Educação a Distância (CIPEAD) e da Coordenadoria de Sistema (COSIS); c. Programa Emergencial de Monitoria Digital (Resolução № 50/20-CEPE), destinado ao apoio às disciplinas e atividades desenvolvidas de forma remota, por meio da Coordenadoria de Atividades Formavas e Estágios (COAFE);

d. orientação e acompanhamento das Coordenações de Curso, Departamentos e demais Unidades Administravas da IESP nos procedimentos administrativos necessários ao desenvolvimento das atividades de ensino dos cursos de educação superior, profissional e tecnológica da IESP em razão das medidas de enfrentamento da pandemia de COVID-19 no País;

III. Ações mandas pela Superintendência de Inclusão, Políticas Afirmavas e Diversidade (SIPAD):

a. acompanhamento de estudantes indígenas, quilombolas, migrantes e refugiados humanitários, surdos e surdas, pessoas com deficiência e com transtornos globais de desenvolvimento, para garantir que suas necessidades específicas sejam atendidas; b. orientação de coordenações e docentes de estudantes indígenas, quilombolas, migrantes e refugiados humanitários, surdos e surdas, pessoas com deficiência e com transtornos globais de desenvolvimento, para garantir que suas necessidades específicas sejam atendidas.

IV. Ação manda pelo Sistema de Bibliotecas da IESP (SiBi/ IESP): 
a. orientação a docentes para o acesso a bases de dados digitais autorizadas para a IESP e outros acervos digitais de acesso público, para qualificação das bibliografias e demais recursos didáticos empregados no ensino remoto emergencial (IESP, 2020, p. 12 e 13).

Embora de caráter voluntário a oferta de disciplinas, o nosso entendimento foi de que a oferta era necessária, de que precisávamos, de alguma forma, estar próximos dos/as estudantes dado o momento de incertezas que estávamos (e continuamos) vivendo. É nesse contexto inédito e confuso que a disciplina Tópicos da Educação Matemática I foi ofertadaministrada.

Antes de adentrarmos na disciplina em si, cabe destacar que o Ensino Remoto Emergencial - ERE não significa uma mudança de modalidade de ensino, mas sim "uma solução temporária e estratégica que permitirá, no contexto da Pandemia de Covid-19, proporcionar à comunidade acadêmica a possibilidade de manter, dentro das circunstâncias possíveis, as atividades de ensino." (CIPEAD, 2020, n.p.).

Ao contrário das experiências planejadas desde o início e projetadas para serem on-line [educação a distância], o ensino remoto emergencial (ERE) é uma mudança curricular temporária e alternativa devido a circunstâncias de crise.

Envolve o uso de soluções de ensino totalmente remotas para instrução ou educação que, de outra forma, seriam ministradas pessoalmente ou em cursos híbridos e que retornarão a esse formato assim que a crise ou emergência arrefecer.

O objetivo principal nessas circunstâncias não é recriar um ecossistema educacional robusto, mas fornecer acesso temporário a instruções e apoios instrucionais de uma maneira que seja rápida de configurar e esteja disponível de maneira confiável durante uma emergência ou crise (HODGES; MOORE; LOCKEE, TRUST; BOND, 2020 apud CIPEAD, 2020, n. p.) (grifos e acréscimos CIPEAD).

A disciplina, de caráter optativo, não faz parte da grade curricular de disciplinas obrigatória do curso de Licenciatura em Matemática da IESP, com isso, todo o planejamento e gerenciamento dela precisou ser construído. Como ela foi ministrada por três docentes, realizamos algumas reuniões para negociar o conteúdo a ser trabalhado e planejar o desenvolvimento da disciplina. Em um primeiro momento, a disciplina tinha como intenção apresentar, conceituar e trabalhar com casos de ensino na formação dos/as futuros/as professores/as de matemática, entretanto durante as reuniões de planejamento percebemos que seria mais oportuno abordar as práticas colaborativas na formação docente, por meio de casos de ensino e estudo de aula. Assim, ficou decidido que o foco da disciplina não seria mais os casos de ensino, mas sim a discussão sobre práticas colaborativas atravessadas dialogicamente por estudos e pesquisas envolvendo casos de ensino (MIZUKAMI e REALI, 2010; PASSOS, 2010; NONO e MIZUKAMI, 2002), estudo de aula (BOAVIDA e PONTE, 2002; ROLDÃO, 2007; PONTE et al, 2016; e FIORENTINI, 2013), alteridade, autoridade e autonomia docente (JESUS, 2018).

A disciplina de $60 \mathrm{~h}$ foi ministrada em sete semanas com aulas sincrônicas semanais e atividades assíncronas, porém além das atividades com os/as estudantes, nós docentes, 
realizávamos duas reuniões semanais, sendo uma antes da aula sincrônica e outra depois, intitulada por nós de resenha da aula. A primeira reunião tinha por objetivo discutir a aula que seria ministrada e a segunda para refletir-resenhar sobre os desafios, os sucessos, as angústias ou tudo que precisasse ser conversado sobre o percurso da disciplina.

O desafio relatado neste trabalho diz respeito também ao fato de estarmos ministrando uma disciplina de forma remota. O entendimento que temos do ERE tem um caráter temporário, que ele é uma forma de continuar as atividades acadêmicas de ensino estimulando a leitura, o estudo e a autonomia dos/as estudantes. Nesta modalidade de ensino a sala de aula invertida é uma estratégia potencialmente interessante, visto que os encontros síncronos devem ser utilizados para discussões e resolução de problemas, por exemplo. Precisamos levar em conta os possíveis problemas de conexão à internet, falta de equipamento adequado, de organização do tempo de estudo, possíveis problemas familiares e de saúde dos/as estudantes e docentes que estão envolvidos/as com as disciplinas nessa modalidade.

O cenário descrito é único, não só pelo momento pandêmico, por vivenciar pela primeira vez o Ensino Remoto Emergencial, mas também por ser uma disciplina ministrada por três vozes docentes. Entendemos que esse trabalho remoto facilitou a realização de uma quantidade maior de encontros entre os três docentes, possibilitou-nos experienciar e construir uma relação de trabalho colaborativo.

\section{Diálogo, negociação e confiança}

O tempo atual, cercado de incertezas e desafios, mostra que precisamos (re)inventar a forma como nos relacionamos, aprendemos, ensinamos ou trabalhamos. A tecnologia se tornou de extrema importância para a continuidade da educação e da sociedade, entretanto como indica Miskulin (2003), nós educadores precisamos estabelecer uma análise crítica frente ao uso da tecnologia para que não ocorra uma banalização dessa ferramenta. Diante disso, discutiremos nessa seção um elemento que em nossa perspectiva pode ser potencializado pelo momento imposto pela pandemia, a colaboração.

A colaboração foi amplamente discutida na educação matemática, principalmente a sua contribuição no desenvolvimento profissional da pessoa docente de matemática. Dentre as características que são inerentes à colaboração destacaremos o diálogo, a negociação, a confiança e o envolvimento de cada participante num trabalho que pretende ser colaborativo. De acordo com Boavida e Ponte (2002), não basta que pessoas formem um grupo para que este seja considerado colaborativo, é necessário que haja um objetivo e uma base de igualdade entre os participantes para que as práticas sejam exercidas, "a colaboração envolve negociação cuidadosa, tomada conjunta de decisões, comunicação efectiva e aprendizagem mútua num empreendimento que se foca na promoção do diálogo profissional." (BOAVIDA E PONTE, 2002, p. 4).

Não existe um modelo de contexto de colaboração, entretanto é necessário que os/as participantes se envolvam com o trabalho a ser desenvolvido para que se possa construir e permanecer a colaboração. Nesse sentido, a colaboração exige que os/as participantes queiram estar ali, ou seja, que a sua participação não seja imposta por instâncias superiores ou artificial. Diante disso, Boavida e Ponte $(2002$, p. 5), expõe que é

[...] fundamental que os participantes manifestem abertura no modo como se relacionam uns com os outros, dispondo-se a um contínuo dar e receber, 
assumindo uma responsabilização conjunta pela orientação do trabalho e sendo capazes de construir soluções para os problemas no respeito pelas diferenças e particularidades individuais.

Uma das características a ser abordada nesse texto é a confiança, que no trabalho que compõe esse relato de experiência, precisou ser desenvolvido e continuamente gerenciada pelas três vozes docentes. A confiança, de acordo com Boavida e Ponte (2002) ocorre a partir de uma escuta atenta do outro, de uma valorização das contribuições e do sentimento de pertencimento ao grupo, assim é importante que as pessoas atrizes envolvidas na colaboração demonstrem respeito e cuidado com o outro. "A confiança é fundamental para que os participantes se sintam à vontade em questionar abertamente as ideias, valores e acções uns dos outros, respeitando-os e sabendo, igualmente, que o seu trabalho e os seus valores são respeitados." (BOAVIDA E PONTE, 2002, p. 7).

A confiança é a porta de entrada para uma outra prática na colaboração, o diálogo. $\mathrm{Na}$ situação desse relato de experiência o diálogo se tornou ainda mais importante, na nossa visão, por ser o modo de interação que mais garantia a "sensação" de presença do outro na reunião, mesmo com todos os desafios impostos pelas reuniões virtuais, as vozes docentes se fizeram presentes. Boavida e Ponte (2002) também abordam o diálogo como uma característica importante da colaboração, consideram que nessa prática a fala das pessoas envolvidas deva ser aceita e considerada na realização-condução do trabalho. Para esses autores o diálogo não deve ser utilizado como ferramenta de fuga dos conflitos, ou seja, o consenso não deve ser idealizado em uma relação colaborativa. O diálogo pode ser entendido na colaboração como o caminho do desafio, na medida em que promove o confronto de ideias e a produção de novos entendimentos.

De acordo com Boavida e Ponte (2002), a colaboração requer negociação, um ajuste no trabalho ou no objetivo sempre que for preciso, um gerenciamento dos relacionamentos e formas de ver o mundo, assim a negociação se torna essencial quando se precisa administrar um problema ou uma crise dentro do grupo. É claro, que podemos perceber que a negociação necessita da confiança e do diálogo em sua execução, uma vez que se faz necessário expor as suas expectativas e exercitar uma escuta atenta das outras vozes pertencentes ao grupo. Como indica Boavida e Ponte (2002), mais do que uma aprendizagem relativa ao problema, a colaboração estimula uma aprendizagem das relações humanas.

\section{A travessia}

Entendemos que a travessia escolhida para construir o presente manuscrito é potente, porque nos convida a partilhar nossas experiências, dando um sentido único, por meio das palavras, daquilo que nos constituiu.

Nomear o que fazemos, em educação ou em qualquer outro lugar, como técnica aplicada, como práxis reflexiva ou como experiência dotada de sentido, não é somente uma questão terminológica. As palavras com que nomeamos o que somos, o que fazemos, o que pensamos, o que percebemos ou o que sentimos são mais do que simplesmente palavras. E, por isso, as lutas pelas palavras, pelo significado e pelo controle das palavras, pela imposição de certas palavras e pelo silenciamento ou desativação de outras palavras são lutas em que se joga algo mais do que simplesmente palavras, algo mais que somente palavras (LARROSA, 2002, p. 21). 
A narrativa para nós assume uma perspectiva para além da ideia de recordar o passo, pois entendemos que ao narrarmos nossa experiência estamos movimentando um certo sentido para aquilo que somos e apresentando as forças que nos constituem. Ao narra-se, "o narrador pode oferecer sua própria continuidade temporal, sua própria identidade e permanência no tempo" (LARROSA, 2011a, p. 69), assim é a partir da narrativa que o sujeito vai constituindo, no tempo narrado, a sua própria identidade. Assim, a narrativa se torna um elemento potencializador em nosso texto, uma vez que narraremos nossas experiências constituindo sentidos individuais para a situação coletiva vivida. Como aponta Larrosa (2011a, p. 69), é "contando histórias, nossas próprias histórias, o que nos acontece e o sentido que damos ao que nos acontece, que nos damos a nós próprios uma identidade no tempo."

As três narrativas compartilhadas (e intituladas) - 'Entre uma garfada e outra, uma resposta por e-mail, por WhatsApp. Será isso o novo normal?', 'Reflexões sobre algumas aprendizagens em uma prática colaborativa' e 'Impressões da minha primeira vez como voz docente em uma disciplina para o curso de licenciatura em matemática' -, privilegiam a singularidade de cada voz docente, apresentando em seus relatos o (a) autor (a), o (a) narrador (a) e personagem construídos(as) por suas narrativas. Apesar de o fato para a construção das narrativas tenha sido negociado, entre as vozes docentes, os pontos a serem abordados nelas (presença e ausência discente, a vivência da disciplina e a avaliação), cada texto apresenta a sua identidade e aquilo que atravessou-afetou a sua experiência. Desejamos compartilhar os afetos e desafetos ao ministrar, remotamente, a três vozes uma disciplina optativa, em meio à pandemia do Covid-19, para o curso de licenciatura em matemática de uma IESP.

\section{Entre uma garfada e outra, uma resposta por e-mail, por WhatsApp. Será isso o novo normal?}

Antes de iniciar a narrativa, que pretende tratar de uma conversa envolvendo os sentidos produzidos-reverberados ao longo de uma disciplina remota ministrada por três vozes docentes, gostaria de dar um testemunho. Aprecio o uso da palavra testemunho, mas ela, do meu ponto de vista, nada tem a ver com qualquer identidade religiosa. $O$ testemunho refere-se à dificuldade de organizar o tempo para sentar, abrir um documento do Word e iniciar a escrita da presente narrativa.

A ideia de escrever um artigo narrando as experiências de três docentes surgiu no final do mês de setembro, logo após o encerramento da disciplina Tópicos de Educação Matemática 1 (TME1) e nos demos um mês para escrever a narrativa individual, tempo suficiente para que pudéssemos revisitarrememorar-ressignificar os acontecimentos de TEM1, contudo, sempre existe algo que precisa de uma atenção especial, pois a sobrecarga de atividades profissionais que assumi, causado, claramente, pela sensação péssima de achar que estava trabalhando menos, posto que não ministrava uma disciplina na graduação desde o dia 13 de março de 2020, quando a Instituição de Ensino Superior Pública (IESP) onde trabalho suspendeu as atividades presenciais, me fez deixar para o último instante, praticamente, nos acréscimos, a escrita da narrativa.

E os acréscimos culminaram com a minha vinda à cidade de São Paulo para visitar a família (irmã e cunhado) que já não via (presencialmente) desde o começo do presente ano. Algo causado pela pandemia do covid-19 refere-se ao fato de que no tempo-espaço-presente o cotidiano profissionalpessoal-social deixou de ter as suas demarcações bem delimitadas e, neste momento, em particular isto se materializa...

Não se trata de uma reclamação e sim constatação, constatação de que as marcações que delimitavam o profissional-pessoal-social foram apagadas, que nos sentimos menos produtivos e por isso preenchemos o nosso tempo com um monte de atividades que, noutrora, não assumiríamos, ...

Feito o testemunho, na sequência, eu gostaria de narrar o que ficou na minha memória da disciplina optativa TEM1 ministrada remotamente por três vozes docentes para o curso de licenciatura 
em Matemática de uma IESP. Cada voz escreveu separadamente a sua narrativa para depois construirmos uma coletivamente e decidimos que cada voz deveria, na medida do possível, tratar de: - a presença e ausência discente, o gerenciamento (vivência da disciplina) e a avaliação -, mas não só e necessariamente isso, pois a colaboração (que será mais destacada em outra parte do nosso artigo), os conflitos, estranhamentos e afetos também reverberam de modo e intensidade diferentes em cada uma das vozes. A minha narrativa será organizada a partir de três títulos, a saber, o antes, o durante e o depois, títulos que não "dizem muito" por si só, mas que traduzem bem o todo (a disciplina) e as partes do todo.

\section{$O$ antes}

A expressão "O antes" tratará do gestar da disciplina que teve duas motivações, a primeira diz respeito à possibilidade de ministrar uma disciplina em parceria com uma voz docente próxima, que me acolheu quando da minha chegada à IESP em agosto de 2017 e, desde então, temos trabalhado em conjunto, sempre que possível, seja na escrita de um artigo, no desenvolvimento de um projeto de extensão, na coorientação de uma dissertação de mestrado, dissertação esta que representa a outra voz docente.

A segunda motivação tem relação direta com a outra voz docente, discente do mestrado em Educação em Ciências e Matemática que precisava cumprir os créditos da "atividade docente" e por conta da pandemia, consequentemente da suspensão do calendário acadêmico não conseguiu cumprir os créditos em outro momento. Decidimos ofertar a disciplina TEM1 (que será detalhada em outro momento do nosso artigo) a três vozes e tendo como fio condutor a colaboração.

Decisão vencida, iniciamos o gestar da disciplina com alguns encontros semanais para decidir o tema, os objetivos, os textos, as atividades assíncronas e os instrumentos de avaliação da TEM1. Acredito que o processo de gestação da disciplina foi pautado pelo diálogo, confiança e negociação, elementos importantes num trabalho colaborativo e, particularmente, eu curti bastante, pois, novamente, o acolhimento se fez presente, nossas vozes ressoavam, quase sempre na mesma direção, entretanto, marcada por conflitos que eram superados pela tríade diálogo-confiança-negociação.

\section{O durante}

A expressão "O durante" tratará da disciplina per se e será formada pelas partes - 'o antes', 'o durante' e 'o depois' - uma vez que nos encontrávamos semanalmente antes da atividade síncrona para organizá-la e depois para fazer a resenha. $O$ sentido produzido do momento 'O antes' foi de tranquilidade, do meu ponto de vista, pois tínhamos delineado bem a disciplina e os encontros eram para ajustar algo que poderia passar despercebido durante as atividades síncronas. A confiança e a empatia com as duas vozes docentes que ministraram a disciplina comigo, também representa um elemento que fortaleceu o sentido de tranquilidade para mim.

O momento 'O durante' numa disciplina da área de Educação Matemática e num curso de licenciatura em Matemática marcado pelas disciplinas da área de Matemática, dificilmente é tranquilo. $E$, novamente, não se trata de uma reclamação, mas sim constatação. Algo recorrente nas conversas durante o desenvolvimento de disciplinas da área de Educação Matemática, do meu lugar de fala, são comentários-argumentações do lugar comum "o texto que estamos discutindo é antigo (final dos anos de 1990)", "não concordo com a autora do texto (teórica dentro da área de Educação Matemática", "não vou discutir questões sociais nas aulas de Matemática, pois isso deve ser tratado por outras disciplinas", "...", "...".

É fato que há textos antigos, é fato que posso discordar da autora, que posso não sentir confiança em tratar de questões sociais nas aulas de Matemática, mas os sentidos que são produzidos por essas falas e nesse espaço são, efetivamente, de descaso com os/as autores/as do texto e com o/a docente que está ministrando a disciplina. Descaso marcado pela crença incutida (para ser leve) na mente dos/as licenciandos/as de Matemática de que basta conhecer o conteúdo matemático para ser um/a bom/a professor/a Matemática e que o ser professor/a de Matemática se aprende na prática. Uma crença próxima à ideia de que o ser professor é um ofício que se aprende praticando, que não há 
necessidade de outros conhecimentos para além do conhecimento matemático. Tal crença míope já deu...

Posto isso, ou melhor, com o sentimento de que precisamos, para além de desenvolver a disciplina, justificar a importância dela e do que estamos circulando teoricamente na disciplina foi que se desenrolou no TEM1. Há outras questões que poderiam ser mobilizadas nesta narrativa, mas que poderiam fugir da proposta inicial, todavia, cabe destacar uma que há uma batalha silenciosa, muitas vezes, uma busca por mostrar que sei o conteúdo matemático e curso licenciatura por desejo e não por 'não dar conta' das disciplinas de Matemática do bacharelado.

Ainda sobre 'o durante', destaco que precisamos, em muitos momentos, direta ou indiretamente para além de desenvolver a disciplinar, justificar a importância dela e do que estávamos circulando teoricamente no TME1 o que dispende uma grande e desnecessária energia, principalmente, pelo fato de não ser uma disciplina obrigatória. Algo que considero oportuno destacar refere-se ao fato de que desenvolver a disciplina a três vozes ajudou a lidar com a questão destacada acima, pois quando a energia de uma das vozes diminuía as outras duas tomavam à frente e assim foi, em alguns momentos mais e em outros menos, a luta semanal em ministrar uma disciplina da área de Educação Matemática em um curso de licenciatura em Matemática fabricado na/pela Matemática Acadêmica.

$O$ momento 'o depois' durante o desenvolvimento da disciplina TME1 refere-se à resenha, possivelmente, uma das experiências mais ricas que tive a oportunidade de viver, pois foram nas resenhas que aparamos as arestas, 'lavamos as roupas sujas', nos acolhemos, nos felicitamos, nos acalmamos, ... Cabe confessar que aguardava mais as resenhas do que os momentos síncronos, não pelo fato de não curtir a disciplina ou os/as licenciandos/as, mas sim pela prática colaborativa que construímos desde a gestação da disciplina.

\section{O depois}

Desejo iniciar o momento "O depois" destacando que a narrativa pretende(u) tratar do lugar de fala do formador e não da pessoa em formação inicial, compartilhando uma pluralidade de sentidossentimentos-afetamentos e ousadamente pretendendo dedicar um espaço para aqueles/as que formam os/as futuros/as professores/as de Matemática da Educação Básica.

Posto isso, gostaria de pontuar que me considero uma pessoa privilegiada, porque pude dedicar um bom tempo para gestar, ministrar e resenhar uma disciplina, algo raro (e ouso escrever utópico) para boa parte dos/as professores/as no Brasil, independentemente, do nível educacional. É fato que outras atividades foram mantidas e acrescidas no meu cotidiano profissional durante a pandemia covid-19, mas isso não muda, do meu ponto de vista, sentir-me uma pessoa privilegiada.

Teria muito mais para narrar, todavia, apesar de sentir-me uma pessoa privilegiada o cansaço mental causado por "Entre uma garfada e outra, uma resposta por e-mail, por WhatsApp" afetousilenciou, neste momento, a minha memória discursiva, entretanto, posso afirmar que a dedicação com que mergulhamos na disciplina foi, genuinamente, verdadeira e intensa, aflorando sentimentossensações para o bem e para o mal, mostrando o cuidado que tivemos com a outra pessoa e tentando praticar o difícil exercício de alteridade.

A verdadeira e intensa dedicação precisa-deve ser movimentada, utopicamente, sempre que possivel, contudo, posso escrever que ela foi potencializada, neste momento, justamente pela possibilidade de trabalhar remotamente, de ministrar uma disciplina com outras duas vozes docentes (algo pouco praticado no curso de licenciatura em Matemática da IESP onde trabalho), proporcionada pela suspensão do calendário acadêmico. Se tivéssemos no antigo "normal" cada um estaria preocupado com as suas disciplinas e suas demandas profissionais-pessoais-sociais que nos impediriam, por exemplo, de fazer a correção coletiva-comentada de todos os trabalhos finais (que iniciou às 14 h e terminou, por volta, das 23h).

Neste momento, eu preciso 'colocar um ponto final', talvez 'um ponto e vírgula' na presente narrativa - como escrevi no início, deixei para produzi-la nos acréscimos, que culminou com a minha vinda à cidade de SP (para visitar a família que já não via desde o começo do ano) - para organizar a minha volta para casa, uma viagem de mais ou menos cinco horas e meia e que farei de carro. 


\section{Reflexões sobre algumas aprendizagens em uma prática colaborativa}

A ideia de fazer uma disciplina conjunta, de forma colaborativa, foi de umas das vozes participantes dessa prática colaborativa, com essa proposta estaríamos atingindo três objetivos, ofertar uma disciplina no período especial com ensino remoto emergencial, que outra voz pudesse fazer a disciplina de prática de docência obrigatória para o mestrado e que pudéssemos trabalhar de forma colaborativa. A princípio não queria aceitar, estava terminando meu mandato como coordenadora do curso e estava me sentindo muito cansada, além disso, queria um tempo para me preparar para uma possível volta do calendário acadêmico quando terminasse o período especial com as aulas de forma remota. No entanto, bastou a primeira reunião de planejamento para mudar de opinião, seria uma experiência muito rica e como eu e as outras vozes trabalhamos juntos na orientação de mestrado de uma delas já tínhamos confiança e abertura para o diálogo, que são considerados características importantes em um grupo colaborativo, entendi que não seria uma tarefa difícil.

Nas duas reuniões de planejamento que se seguiram e com várias ideias surgindo, mudamos o foco da disciplina de casos de ensino para as práticas colaborativas e acrescentamos textos referentes ao estudo de aulas, práticas colaborativas e questões da alteridade, autoridade e autonomia docente. Definimos os objetivos da disciplina, o programa, o cronograma, a forma de avaliação, dia da semana para aula síncrona e plataforma que utilizaríamos. Todas as questões burocráticas foram organizadas, mas para isso foi necessária uma boa dose de negociação para que o entendimento de cada um de nós sobre a disciplina, a metodologia utilizada e a forma de avaliação fossem de alguma forma contempladas. A disciplina com carga horária de $60 \mathrm{~h}$ ficou estruturada em 6 semanas, teríamos uma aula síncrona toda a semana com aproximadamente $3 \mathrm{~h}$ de duração. Posso dizer que para mim foi tudo muito intenso nessas 6 semanas e foi um período de autoconhecimento e autoavaliação.

Enquanto os alunos tinham suas tarefas de leitura, fichamentos e relatos de aula, nós fazíamos duas reuniões durante a semana, uma anterior a aula para planejamento e outra depois da aula para fazemos uma avaliação do que aconteceu.

Nas reuniões para planejamento da aula da semana, embora divertidas, eram uma fonte de ansiedade para mim, pois pensava que deveríamos estar discutindo a aula da semana seguinte. Isso porque quando faço uma disciplina pela primeira vez, gosto de pensar que tenho controle do que possa acontecer, gostaria de ter discutido os textos anteriormente, para que pudéssemos ter maior clareza de alguns pontos e de como conduzir a aula, isso me deixaria mais tranquila, mas essa demanda era minha. Nós fazíamos isso, mas não com antecedência que me acalmasse. Quando estou sozinha não tem problema se algo não sair como planejado, os erros ou as consequências deles não afetam outras pessoas que planejaram a disciplina.

Como aconteceu em uma aula, em que uma das vozes pediu para que os alunos falassem sobre o texto, uma rodada de comentários e que depois iríamos falar sobre alguns pontos importantes do texto. Como a aluna começou a falar sobre o final do texto, pedi para que seguíssemos a ordem do texto, pois achei que não conseguiríamos voltar a ele, já que o que ela estava falando era sobre a inclusão de pessoas com necessida des especiais e como os professores e a escola tratam dessa questão. Esse é um tema controverso, cheio de crenças, opiniões do senso comum e carregado de emoção, e não era o foco da discussão. O texto falava sobre casos de ensino, o que era, como poderia ser usado, discutia as potencialidades do seu uso na formação de professores e um dos casos apresentados contava como uma professora lidava com um estudante com necessidades especiais em sua aula. Neste momento essa mesma voz pediu para que eu deixasse os alunos falarem o que acharam importante no texto e depois a gente retomaria do início. Então deixamos que os estudantes seguissem com suas observações, mas eles se distanciaram do assunto principal do texto e ficamos mais tempo do que gostaríamos em uma conversa sem sentido e foi difícil retornar ao texto e discutir o que achávamos importante para o restante da disciplina e para o trabalho final que os estudantes deveriam fazer.

No restante dessa aula apresentamos aos estudantes um exemplo de caso de ensino, como eu era a responsável por fazer essa discussão fiz a leitura do texto. Enquanto discutia o texto com os alunos em alguns momentos que chamei as outras vozes para complementar alguma ideia e eles não 
respondiam ou diziam que não tinham nada para complementar. Eu estava confiando que eles estivessem participando da aula junto comigo, a minha expectativa era que conduzíssemos a aula juntos e que pudéssemos complementar as ideias um do outro, mesmo eu sendo a responsável pela condução da discussão. Depois dessa aula, que foi a segunda aula e primeira em que estávamos realmente discutindo algum texto com os alunos, eu fiquei com mais medo de cometer algum erro e ser responsável por algo que não desse certo. Esses imprevistos são naturais em uma sala de aula, nem sempre o assunto chama a atenção dos alunos, às vezes, como nesse episódio, o que afeta as pessoas não está em jogo na aula, mas é o sobre isso que eles querem falar. A falta da interação de uma aula presencial em que levamos em conta o olhar e a linguagem corporal das pessoas, fez com que eu perdesse a referência para interromper uma fala ou mudar o assunto.

Ao mesmo tempo fiquei responsável por ler os relatos de aula que os estudantes deveriam escrever e percebi por esses relatos que eles não entenderam o que era um caso de ensino e que precisávamos reforçar a ideia de caso de ensino, pois elaborar um caso de ensino fazia parte da avalição dos estudantes na disciplina. Fizemos isso, mas nas duas últimas semanas os alunos ainda estavam inseguros quanto a esse trabalho, dúvidas como: o que fazer, com quem, se poderia ser professor do ensino superior ou não. Eu entendi com essas questões que eles não tinham entendido ainda o que era o caso de ensino e que precisaríamos conversar sobre isso novamente. Mas o entendimento das outras vozes foi diferente, para eles os estudantes tinham vários exemplos, poderiam ler novamente os textos indicados e que não deveríamos usar mais uma aula para falar sobre isso com eles. Iríamos dar as respostas sobre as outras questões, mas não falaríamos mais sobre o que é um caso de ensino, esse foi só um exemplo das várias negociações que tivemos de fazer. Em geral, eu sou protetora e controladora em todas as atividades que proponho para os alunos, mas nesse caso, não poderia tomar para mim a responsabilidade do não entendimento dos alunos. Sempre digo que a maior parte do aprendizado é de responsabilidade do aluno e sempre caio na armadilha de que tenho de fazer mais por eles.

O período de realização dessa disciplina fez com que as coisas fossem rápidas, as decisões tinham de ser tomadas rapidamente e eu não poderia tomar essas decisões sozinha. Na maioria das vezes os alunos tiravam suas dúvidas comigo, não utilizando o Moodle que era a plataforma que estávamos usando e que deveria ser o nosso meio de comunicação. Eu, infelizmente, não tomei a atitude de pedir para que essas dúvidas fossem postadas na plataforma também, o que pode ter gerado um conflito entre nós, pois eu precisava chamá-los fora do horário das nossas reuniões habituais para responder aos alunos. Nem sempre os outros docentes estavam disponíveis, nem sempre queriam ou podiam parar o que estavam fazendo para me atender e atender aos alunos. No início achei que fosse falta de dedicação com a disciplina, mas depois entendi que era um limite que eles colocaram em sua rotina, e eu não. Estar o tempo todo a disposição dos alunos ou a disciplina, fez com que minha ansiedade aumentasse mais. Uma lição óbvia para disciplinas realizadas de modo colaborativo é que as regras e os limites devem ser claros para todos e acatados por todos.

Algo muito interessante que fizemos foi conversar depois de cada aula sobre nossas percepções sobre ela, o que deu certo e o que não deu, o que precisaríamos mudar, o que precisaríamos conversar com os estudantes para que respondessem e participassem mais das aulas. Essas reuniões chamadas de 'resenha da aula' por uma das vozes foram para mim mais que um momento de avaliação, foi uma forma de terapia, de autoconhecimento, e ao mesmo tempo um exercício de escuta atenta para não atravessar a fala do outro. Estranho como as conversas ficaram mais difíceis e ao mesmo tempo mais organizada usando as chamadas de vídeo. Quando estamos presencialmente a linguagem corporal está visivel, a interrupção de uma fala não se parece com um corte de transmissão ou falha do aplicativo. Presencialmente parece ser possivel complementar a ideia do outro sem parecer tão rude interrompendo sua fala.

Várias vezes pareceu que o tempo para colocar a minha opinião tinha passado, demorava mais para entender a ideia da outra pessoa e formular o meu raciocínio, como se houvesse um atraso na chegada e processamento da informação para que eu pudesse comunicar essa opinião. Não sei o 
porquê dessa sensação, talvez o cansaço de horas na frente de computador, sendo obrigada a me concentrar mais do que o normal para ouvir e entender o que as outras pessoas estavam dizendo.

Nessas reuniões algo muito interessante também foi acompanhar o desenvolvimento de uma das vozes em sua experiência como docente responsável por uma disciplina da graduação, a ideia era que ela dividisse igualmente a disciplina conosco e não apenas observasse, o que ela fez com maestria. Foi impossível não se identificar com a frustração dela ao perceber que alguns estudantes não estavam se dedicando a disciplina, tanto quanto ela entendia que eles deveriam, ou que estão mais preocupados em simplesmente passar na disciplina e não na sua formação. Essa foi uma situação em que tivemos que acolher, conversar e dividir que essa é uma percepção que, infelizmente, temos quando trabalhamos com disciplinas ligadas a questões de da Educação Matemática.

Com relação não participação dos estudantes durante as aulas, foi frustrante. Estávamos a alguns meses sem aulas e a vontade de interação com os estudantes era grande. $O$ modo remoto de ensino dá a eles mais condições para que fiquem ausente durante as discussões, não ligar a câmera é só uma delas, eles também podem simplesmente ignorar as perguntas mesmo com a câmera ligada. Não que não exista versões para estes comportamentos no modelo presencial, mas presencialmente ainda temos o olhar nos olhos, que nos diz muita coisa.

No final, o que era para ser uma disciplina tranquila, para atender uma demanda dos nossos estudantes que precisavam continuar de alguma forma seus estudos, se transformou em um grande desafio e aprendizado. Principalmente sobre como trabalhar de forma colaborativa, ver e sentir na prática as negociações necessárias para se atingir os objetivos, ceder em vários pontos nessas negociações, quebrar e reconstruir a confiança nos colegas, experimentar todas as dificuldades inerentes a esse tipo de trabalho. No meu caso, ainda controlar a ansiedade, a vontade de resolver tudo sozinha do meu jeito e não desagradar as pessoas. Foi fácil? Não. Faria novamente? Com certeza.

\section{Impressões da minha primeira vez como voz docente em uma disciplina para o curso de licenciatura em matemática}

Eu sou aluna do segundo ano do mestrado do curso de Pós-Graduação em Educação em Ciências e Matemática, além disso sou bolsista da CAPES e umas das exigências da Instituição é que os alunos bolsistas dos programas de pós-graduação realizem prática à docência durante o período de vigência da bolsa. No início do ano, eu iniciei a prática de docência, em uma disciplina obrigatória do curso de licenciatura em Matemática da IESP da qual sou aluna, essa disciplina chegou a ser iniciada, mas por conta da pandemia ela foi suspensa, assim como o calendário da instituição. Após um período com o calendário suspenso, a IESP tomou a decisão de abrir um período especial, que manteria o calendário da instituição interrompido, mas possibilitaria para os docentes e discentes que pudessem, em caráter não obrigatório, oferecer disciplinas na modalidade remota. É desta forma que chego até o curso Tópicos de Educação Matemática I, uma disciplina optativa ministrada de forma remota para o curso de licenciatura em matemática e que possibilitou com que eu realizasse a prática de docência. Entretanto como a prática da docência não tem uma forma a ser seguida pelos alunos, fica na responsabilidade do professor da disciplina juntamente com o mestrando decidir como será a sua participação na disciplina, assim, pensando na minha formação questionei os meus orientadores, que iriam ofertar a disciplina, se havia a possibilidade de observá-los elaborando e preparando o curso que seria ministrado para a graduação, uma vez que eu percebi que o momento da pandemia me possibilitaria ver como era pensar e preparar uma disciplina ofertada para o curso superior. A resposta para a minha pergunta foi melhor do que eu esperava, os dois docentes, me convidaram a participar como professora da disciplina, propondo que eu participasse de todo o desenvolvimento do curso com eles e me tornasse uma voz docente nessa disciplina.

Em um primeiro momento pode parecer uma tarefa fácil, ministra uma disciplina em três professores, afinal são três pessoas para contribuir com as suas perspectivas profissionais. Mas o que esqueci é que essas três pessoas são singulares, que cada uma tem a sua formação que Ihes torna um professor e uma professora exclusiva, e tudo isso fica mais intenso quando se constrói uma relação de 
trabalho colaborativo. Não quero que a singularidade de cada professor, seja vista como um ponto negativo nessa experiência de colaboração, mas como um tensionamento que tornou o experienciar a colaboração mais significativa, uma vez que o outro vê o mundo de outra forma por conta da sua formação. É este processo, de diálogos, conflitos, negociações e confiança vivenciados em um trabalho colaborativa que tornaram a elaboração e execução da disciplina um desafio e uma autoformação.

Quero começar relatando que trabalhar em colaboração não é simples e nem pode ser reduzido ao fato de se ter um grupo trabalhando junto. Nós três, tivemos que ao longo das reuniões realizadas constituir um ambiente de colaboração, tivemos que definir um objetivo que atingisse a todos e que fosse ao encontro dos objetivos individuais de cada um. Essa disciplina, como mencionei anteriormente, foi ministrada de forma remota por conta da pandemia, desta forma todas as reuniões que realizamos foram nesse ambiente virtual, que como descreverei mais adiante, tem seus prós e contras. Mas em um primeiro momento quero mencionar que o ensino dessa forma, em caráter emergencial, possibilitou com que eu participasse de todo um processo de elaboração de uma disciplina optativa, que provavelmente em uma realidade sem pandemia e sem ensino remoto não fosse possível. Acredito, na experiência aqui relatada, que a principal contribuição do trabalho de forma remota foi na influência para a construção da relação colaborativa, penso que a quantidade de encontros realizados para construir o curso, para planejar as aulas e posteriormente refletir sobre elas exigiu um maior envolvimento de nós professores, que na minha perspectiva foi acolhida por todos. Nós três decidimos se envolver com as tomadas de decisões, com as negociações e com o gerenciamento de conflitos, que consequentemente resultou em uma quantidade maior de trabalho e dedicação.

Nós realizamos alguns encontros antes do início da disciplina, para juntos decidirmos o que seria ministrado, quais os referenciais teóricos, como seria a avaliação, ou seja, todas as decisões que envolveram a criação da disciplina foram tomadas pelos três professores. Durante a execução do curso, realizamos semanalmente dois encontros, um antes de cada aula a ser dada na semana, para discutirmos como seria a sua realização e um segundo, que no meu entendido era o mais importante, para fazermos uma "resenha" (reflexão e análise crítica) da aula. Esses momentos normalmente duravam horas, porque o grupo era muito participativo, atribui-o esse envolvimento a confiança que nós três construímos. Um elemento que foi essencial para me sentir confortável durante as reuniões e expressar aquilo que me incomodou, o que eu sentia em relação com os alunos, de que forma eu acreditava que poderíamos "melhor" a condução das aulas e as angústias de estar vivendo pela primeira vez o ensino em nível superior.

No meu caso, o ambiente colaborativa foi mais acolhedor que a minha experiência durante as aulas, nas quais eu não me sentia autorizada como professora, mesmo que em nenhum momento tenha sido feito uma diferenciação para os alunos entre as três vozes docentes, por conta da diferença de experiência como docente no ensino superior, em sala de aula eu preferia sair de cena e não atuar tanto como docente. Um outro elemento que contribui para esse meu desconforto em sala de aula foram os inúmeros questionamentos que eu me colocava sobre como deveria me comportar como professora de uma disciplina para o curso de licenciatura em matemática. As outras duas vozes docentes sempre me trataram como uma colega, ou seja, autoridade que os dois possuíam na disciplina, era também estendida para mim, no sentido de autorizar-se a estar ali para exercer o papel de professora, entretanto por algum motivo durante as aulas eu sentia dificuldade de exercer tanto a autoridade como a autonomia, muito diferente do que acontecia nas reuniões em que o nosso trabalho era exercido em uma base de colaboração.

Por ser uma disciplina pensada por três professores a negociação e o conflito foram elementos que estiveram presentes nesse trabalho colaborativo. Quero aqui destacar um momento, em que tivemos de gerenciar um conflito que de certa forma precisou ser dialogado para que a confiança e a prática de colaborar não se perdesse no caminho. Em uma das aulas, a minha participação foi substituída pela minha ausência, mesmo estando presente senti dificuldade de compreender os alunos e dialogar com eles sobre o tema que deveria ser abordado na aula. Desta forma, decidi deixar que uma das outras duas vozes docente conduzisse sozinha, de tal forma que quando era questionada eu 
não tinha muito a acrescentar e tentava rapidamente passar a "bola" para ela. Na reunião após essa aula, a docente manifestou o seu descontentamento, com o fato de ter que direcionar sozinha a aula, sem poder contar comigo e nem com a outra voz docente, uma vez que tínhamos atribuído a responsabilidade da condução da aula a ela sem uma negociação anterior. Nesse momento, o diálogo e a confiança foram essenciais para se administrar a situação que havia sido exposta, precisamos analisar de forma crítica a situação para identificarmos o que tinha causado aquela situação, e quais caminhos poderíamos tomar para que ela não voltasse a se repetir. Ficou esclarecido que o meu distanciamento, foi pelo obstáculo de não encontrar nas discussões realizadas pelos alunos durante a aula um aprofundamento sobre o tema abordado, e como não sabia como conduzi-los ao que estava desejando para a aula deixei a condução com a voz docente que se destacava naquele momento. Eu encontrei uma frustração nas aulas, como conduzir os alunos a uma discussão teórica mais profunda?

A falta de aprofundamento nas discussões teórica foi uma das minhas decepções com a disciplina, acredito que um dos motivos dessa insatisfação ter ocorrido, foi pelo desafio da interação no ensino remoto, entre elas a dificuldades tecnológicas que impossibilitava alguns alunos de serem vistos, a falta de participação deles durante a aulas e o cansaço imposto pelo trabalho remoto. Entretanto, as reuniões juntamente com o acolhimento dos outros dois professores, me possibilitaram externalizar e refletir sobre essas dificuldades, ao dividi-las foi possível discutir e negociar caminhos para que a disciplina se tornasse mais dinâmica. Desta forma, entendo que o espaço colaborativo construído por todos nós possibilitou um escutar juntamente com o diálogo. As reuniões, antes e após a aula, me auxiliaram a pensar na minha formação, a qual na minha visão, foi potencializada por um constante "dar e receber". Ao analisarmos o nosso trabalho, nas tomadas de decisões, nas inquietações que cada um sentia com as aulas e a visão crítica de cada professor sobre o seu trabalho externalizadas durante as reuniões, possibilitaram com que eu aprendesse sobre o ensino em nível superior. Desta forma, entendo que as reuniões contribuíram para a minha formação como futura formadora de professores de matemática, uma vez que todos os desafios impostos pela minha primeira experiência no ensino superior foram compartilhados e trabalhados nos encontros.

Eu entendo, que o maior desafio na execução dessa disciplina tenha sido no trabalhar em colaboração, uma vez que essa perspectiva requer um diálogo constante. Como todos participavam na tomada de decisões, muitas das vezes não havia uma concordância mútua sobre o que deveria ser feito, nesse caso o diálogo não foi exercido no sentido do consenso, mas na direção de encontrar uma solução em que todos se vissem responsável por ela. Nesse sentido, trabalhar na perspectiva remota auxiliou na quantidade de reuniões que foram possíveis de serem realizadas, que em uma outra perspectiva poderia causar uma certa dificuldade. Uma das dificuldades impostas pelo trabalho remoto é a realização da interação de que estamos acostumados e que para uma proposta colaborativa é essencial, desta forma a decisão de todos os professores de se envolverem com nas tomadas de decisões, nas negociações e de estabelecer um diálogo foram primordial para a construção $e$ manutenção do trabalho colaborativo durante as reuniões.

Para finalizar, acredito ser importante destacar que o sucesso do trabalho colaborativo que ocorreu entre nós três, só foi possível mediante o envolvimento de cada professor com o trabalho. Uso a palavra sucesso não no sentido de que o trabalho colaborativo não possua conflito, ou que negociar e dialogar sejam simples, mas no sentido de que os desafios impostos pelo ensino remoto juntamente com um envolvimento de todos nas trocas realizadas durante as reuniões, garantiram uma possibilidade de reinventar em um momento de emergência posta por uma pandemia.

\section{Impressões Finais}

Como o objetivo desse texto é narrar as experiências de três vozes formadoras ao ministrar, por meio do Ensino Remoto Emergencial, uma disciplina optativa em um curso de licenciatura em matemática de uma IESP durante a pandemia, escrevemos as narrativas acima. 
Essas narrativas foram escritas individualmente no intervalo de um mês entre o final da disciplina e a data que estipulamos para a entrega. Dessa forma entendemos que o que foi colocado nessas narrativas são episódios, situações e sensações que nos tocaram, atravessaram as nossas experiências. Assim apresentamos a seguir alguns sentidos que, na nossa perspectiva, atravessam as narrativas.

\subsection{Se adaptar ao momento é preciso}

O que levou cada voz a participar da execução da disciplina, apresenta como esse momento da pandemia e de trabalho remoto têm afetado de forma diferente cada indivíduo. Seja "pela sensação péssima de achar que estava trabalhando menos", ou pela possibilidade de viver "uma experiência muito rica", ou pela necessidade de "realizar a prática de docência" cada voz docente foi atravessada por uma motivação, mas que possui algo em comum, a inevitável adaptação ao momento posto pela pandemia do Covid-19. Um sentido que queremos destacar aqui, é a adaptação, adaptação a forma de trabalhar, ao espaço de trabalho, entre outras mudanças de planos que foram necessárias para sobreviver a esse momento da melhor forma possível. O discurso da adaptação, já faz parte da constituição do sujeito, entretanto no Ensino Remoto Emergência, a sua prática se torna inevitável, e podemos cair na armadilha de romantizá-la. As experiências aqui relatas, não escapam da adaptação, trabalhar de forma colaborativa foi uma forma de se adaptar a situação atual, mas os relatos também destacam as dificuldades e os desafios frente à indispensabilidade da adaptação. Destacamos alguns momentos das narrativas, que acreditamos evidenciar o trabalho colaborativo como a forma encontrada pelas/os três docentes para se adaptarem à circunstância de trabalho em meio a uma pandemia.

A verdadeira e intensa dedicação precisa-deve ser movimentada, utopicamente, sempre que possivel, contudo, posso escrever que ela foi potencializada, neste momento, justamente pela possibilidade de trabalhar remotamente, de ministrar uma disciplina com outras duas vozes docentes (algo pouco praticado no curso de licenciatura em Matemática da IESP onde trabalho), proporcionada pela suspensão do calendário acadêmico. Se tivéssemos no antigo "normal" cada um estaria preocupado com as suas disciplinas e suas demandas profissionais-pessoais-sociais que nos impediriam, por exemplo, de fazer a correção coletiva-comentada de todos os trabalhos finais (que iniciou às $14 \mathrm{~h}$ e terminou, por volta, das 23h). (Narrativa Entre uma garfada e outra, uma resposta por e-mail, por WhatsApp. Será isso o novo normal?)

A princípio não queria aceitar, estava terminando meu mandato como coordenadora do curso e estava me sentindo muito cansada, além disso, queria um tempo para me preparar para uma possível volta do calendário acadêmico quando terminasse o período especial com as aulas de forma remota. No entanto, bastou a primeira reunião de planejamento para mudar de opinião, seria uma experiência muito rica e como eu e as outras vozes trabalhamos juntos na orientação de mestrado de uma delas já tínhamos confiança e abertura para o diálogo, que são considerados características importantes em um grupo colaborativo, entendi que não seria uma tarefa difícil. (Narrativa Reflexões sobre algumas aprendizagens em uma prática colaborativa)

Acredito, na experiência aqui relatada, que a principal contribuição do trabalho de forma remota foi na influência para a construção da relação colaborativa, penso que a quantidade de encontros realizados para construir o curso, para planejar as aulas e posteriormente refletir sobre elas exigiu um maior envolvimento de nós professores, que na minha perspectiva foi acolhida por todos. (Narrativa Impressões da minha primeira vez como voz docente em uma disciplina para o curso de licenciatura em matemática). 
A colaboração não foi somente uma forma de trabalho potencializado pelo trabalho remoto, mas uma maneira de se adaptar à necessidade de ministrar uma disciplina durante o EME. Assim, as ferramentas confiança-diálogo-negociação tão presentes na colaboração, foram essenciais para se compartilhar, ouvir, ver e sentir o outro presente em um momento que a presença física perde espaço. Não queremos aqui apresentar a colaboração como uma verdade absoluta para o momento que pede adaptação, mas como uma possibilidade de vivenciar, experienciar e pensar esse momento.

\subsection{0 trabalho remoto potencializou a colaboração}

Uma outra marca presente nas narrativas, é a impressão de que ministrar a disciplina de forma remota possibilitou (ou potencializou) a colaboração. Nesse sentido, queremos refletir sobre os sentidos que foram produzidos pela colaboração constituída nas inúmeras reuniões realizadas de forma virtual. Pensamos que os encontros realizados de forma remota possuem as suas vantagens e desvantagens. Como mencionado nas narrativas estes encontros juntamente com a decisão das vozes docentes de se envolverem com o trabalho a ser realizado intensificaram as relações existentes entre os/as três docentes.

(...) posso afirmar que a dedicação com que mergulhamos na disciplina foi, genuinamente, verdadeira e intensa, aflorando sentimentos-sensações para o bem e para o mal, mostrando o cuidado que tivemos com a outra pessoa e tentando praticar o difícil exercício de alteridade. (Narrativa Entre uma garfada e outra, uma resposta por e-mail, por WhatsApp. Será isso o novo normal?).

Ao mesmo tempo, alguns limites de tempo-espaço deixavam de existir, fronteiras que são bem demarcadas quando trabalhados de forma presencial, mas que nesse momento precisaram ser redefinidas e negociadas.

Na maioria das vezes os alunos tiravam as suas dúvidas comigo, não utilizando o Moodle que era a plataforma que estávamos usando e que deveria ser o nosso meio de comunicação. Eu, infelizmente, não tomei a atitude de pedir para que essas dúvidas fossem postadas na plataforma também, o que pode ter gerado um conflito entre nós, pois eu precisava chamá-los fora do horário das nossas reuniões habituais para responder aos alunos. Nem sempre os outros docentes estavam disponiveis, nem sempre queriam ou podiam parar o que estavam fazendo para me atender e atender aos alunos. No início achei que fosse falta de dedicação com a disciplina, mas depois entendi que era um limite que eles colocaram em sua rotina, e eu não. Estar o tempo todo à disposição dos alunos ou da disciplina, fez com que minha ansiedade aumentasse mais. Uma lição óbvia para disciplinas feitas de modo colaborativo é que as regras e os limites devem ser claros para todos e acatados por todos. (Narrativa Reflexões sobre algumas aprendizagens em uma prática colaborativa).

Além da necessidade dos limites, uma outra questão indispensável foi o envolvimento de todas as vozes docentes, no diálogo, na negociação, na constituição da confiança e na construção de uma presença mesmo que a distância.

Durante a execução do curso, realizamos semanalmente dois encontros, um antes de cada aula a ser dada na semana, para discutirmos como seria a sua realização e um segundo, que no meu entendido era o mais importante, para fazermos uma "resenha" (reflexão e análise crítica) da aula. Esses momentos normalmente duravam horas, porque o grupo era muito participativo, atribuo esse envolvimento à confiança que nós três construímos. (Narrativa Impressões da minha primeira vez como voz docente em uma disciplina para o curso de licenciatura em matemática)

Assim, percebemos que o trabalho remoto intensificou a criação de uma relação colaborativa entre as três vozes docentes, mas esse não foi o único elemento que esteve presente nessa formação do grupo como colaborativo, na nossa perspectiva, o envolvimento de cada docente no diálogo, a escuta atenciosa realizada com o que a outra voz trazia, a 
participação na negociação e tomada de decisões foram, e talvez sejam, os elementos mais significativos para o sentido de que o trabalho remoto potencializou a colaboração. Pensamos no fato de que esse sentido pode (e deve) estar relacionado à energia que é necessária dispor nas interações realizadas com o ensino remoto, ou seja, a presença que a colaboração exige foi intensificada pelo trabalho remoto e pelo envolvimento de cada voz docente em todas as demandas da disciplina.

Queremos finalizar esse relato de experiência, reforçando que a relação construída ao longo da execução da disciplina, do nosso ponto de vista, foi uma forma de se adaptar e reinventar as relações humanas em um período em que a presença se torna escassa, ausência. A colaboração não é um assunto novo, mas, nesse caso, ela produziu o sentido de envolvimento, de dedicação, de desafios, entre outros mencionados ao longo das três narrativas. Essa relação exercida ao compartilhar uma disciplina de forma remota e em meio a uma pandemia, se tornou para as três vozes docentes uma possibilidade de estabelecer conexões e vivenciar esse momento cercado de incertezas e novidades.

\section{Referências}

BOAVIDA, Ana Maria; PONTE, João Pedro. Investigação colaborativa: Potencialidades e problemas. In GTI (Org), Reflectir e investigar sobre a prática profissional. p. 43-55. Lisboa: APM, 2002.

COORDENADORIA DE INTEGRAÇÃO DE POLÍTICAS DE EDUCAÇÃO A DISTÂNCIA - CIPEAD. ERE Ensino Remoto Emergencial. Disponível em:

http://www.cipead.iesp.br/portal1/index.php/cipead/periodo-especial-iesp/ere-ensino-remotoemergencial/. Acesso em: 20 nov. 2020.

FIORENTINI, Dario. Pesquisar práticas colaborativas ou pesquisar colaborativamente? In: BORBA, M. de C.; ARAÚJO, J. de L. (organizadores). Pesquisa Qualitativa em Educação Matemática. 5a ed. 144 p. (Tendências em Educação Matemática, 9). Belo Horizonte: Autêntica Editora, p. 53-86, 2013.

INSTITUIÇÃO DE ENSINO SUPERIOR PÚBLICA - IESP. Conselho de Ensino, Pesquisa e Extensão (CEPE). Resolução no 59/2020 - CEPE. Cidade, 2020.

JESUS, Humberto Luis de. Sobre alteridade, autonomia, autoridade e saberes docentes nas aulas de matemática. 596 f. Tese (Doutorado em Educação). Faculdade de Educação, Universidade de São Paulo, São Paulo, 2018.

LARROSA, Jorge. Notas sobre a experiência e o saber de experiência. Revista Brasileira de Educação, Rio de Janeiro, n. 19, p. 20-28, jan./fev./mar./abr., 2002.

LARROSA, Jorge. Experiência e alteridade em Educação. Revista Reflexão e Ação, Santa Cruz do Sul, v.19, n. 2, p. 04-27, jul./dez., 2011.

LARROSA, Jorge. Tecnologias do EU e Educação. In: SILVA, T. T. (organizador). 0 sujeito da Educação. 8ª ed. 260 p. Petrópolis: Vozes, p. 35-86, 2011a.

PASSOS, Cármen Lúcia Brancaglion. (organizadora). Processos de formação de professores: narrativas, grupo colaborativo e mentoria. 74 p. - (Coleção UAB-UFSCar). São Carlos: EdUFSCar, 2010. 
MISKULIN, Rosana Giaretta Sguerra. As possibilidades didático-pedagógicas de ambientes computacionais na formação colaborativa de professores de matemática. In: FIORENTINI, D. (organizador). Formação de professores de matemática: explorando novos caminhos com outros olhares. Campinas: Mercado de Letras, p. 217-248, 2003

MIZUKAMI, Maria da Graça Nicoletti; REALI, Aline Maria de Medeiros Rodrigues. (organizadoras). Aprendizagem profissional da docência: saberes, contextos e práticas. São Carlos: EdUFSCar, 2010.

NONO, Maria Anabel; MIZUKAMI, Maria da Graça Nicoletti. Casos de ensino e processos de aprendizagem profissional docente. Revista Brasileira de Estudos Pedagógicos - RBEP, Brasília, v. 83, n.203/204/205, p. 72-84, jan./dez., 2002.

PONTE, João Pedro da.; QUARESMA, Marisa; PEREIRA, Joana Mata; BAPTISTA, Mónica. O Estudo de Aula como Processo de Desenvolvimento Profissional de Professores de Matemática. Bolema, Rio Claro (SP), v. 30, n. 56, p. 868 - 891, dez. 2016.

ROLDÃO, Maria do Céu. Colaborar é preciso: Questões de qualidade e eficácia no trabalho dos professores. NOESIS, Lisboa, n. 71, p. 24-29, out./dez., 2007. 